\title{
Queer Men, Affect, \& Physical Education
}

\author{
Dillon Landi \\ Ph.D. Candidate
}

The University of Auckland

(New Zealand) 


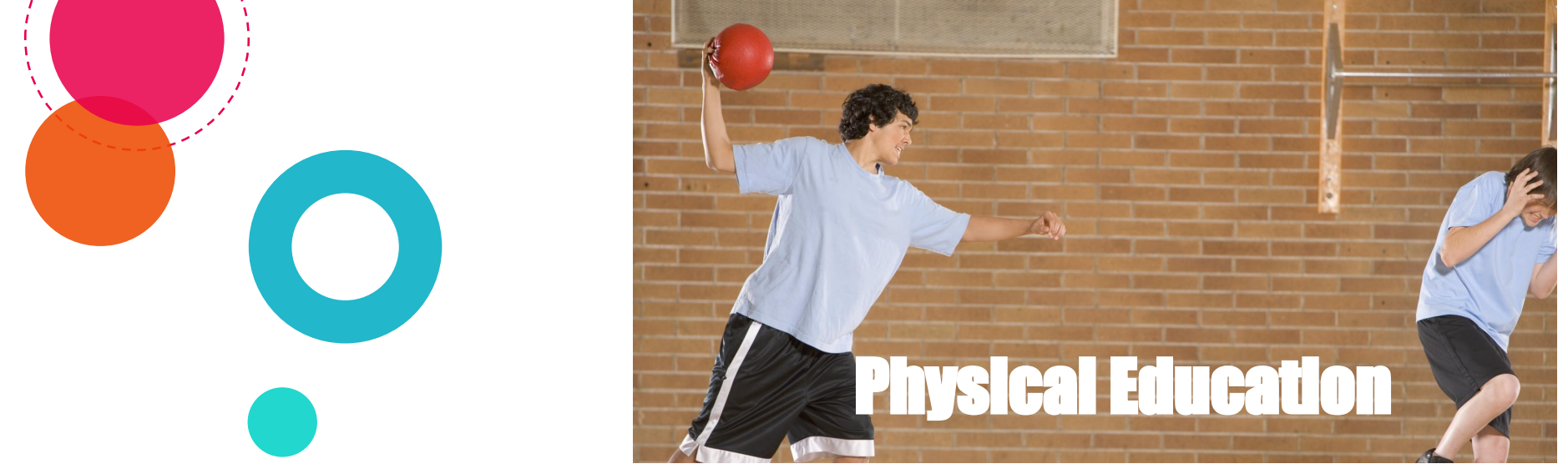

- PE has reproduced traditional forms of gendered practices that align to heteronormativity (Brown, 2005; Gard, 2001; Hunter, 2005; Penney, 2002; Sykes, 2011; Wright, 1997).

- Many scholars (e.g. Clarke, 1998; 2000; Gill et al., 2006; McGlashan, 2013; Morrow \& Gill, 2003; Sykes, 2011) have found PE to be engrained with heterosexist and homophobic discourses. 
(a) Clarke (2006) claims the lack of research on queer male experiences is "a sad indictment of much of the physical education profession and wider western society" (p. 730).

(D) Very little discussion of homoerotic desire in physical education settings (Sykes, 2003)

Binaries:

- Bodies (natural/ social)

- Identities (essentialist/ constructivist) 


\section{New Materialism:}

Deleuze \& Guattari

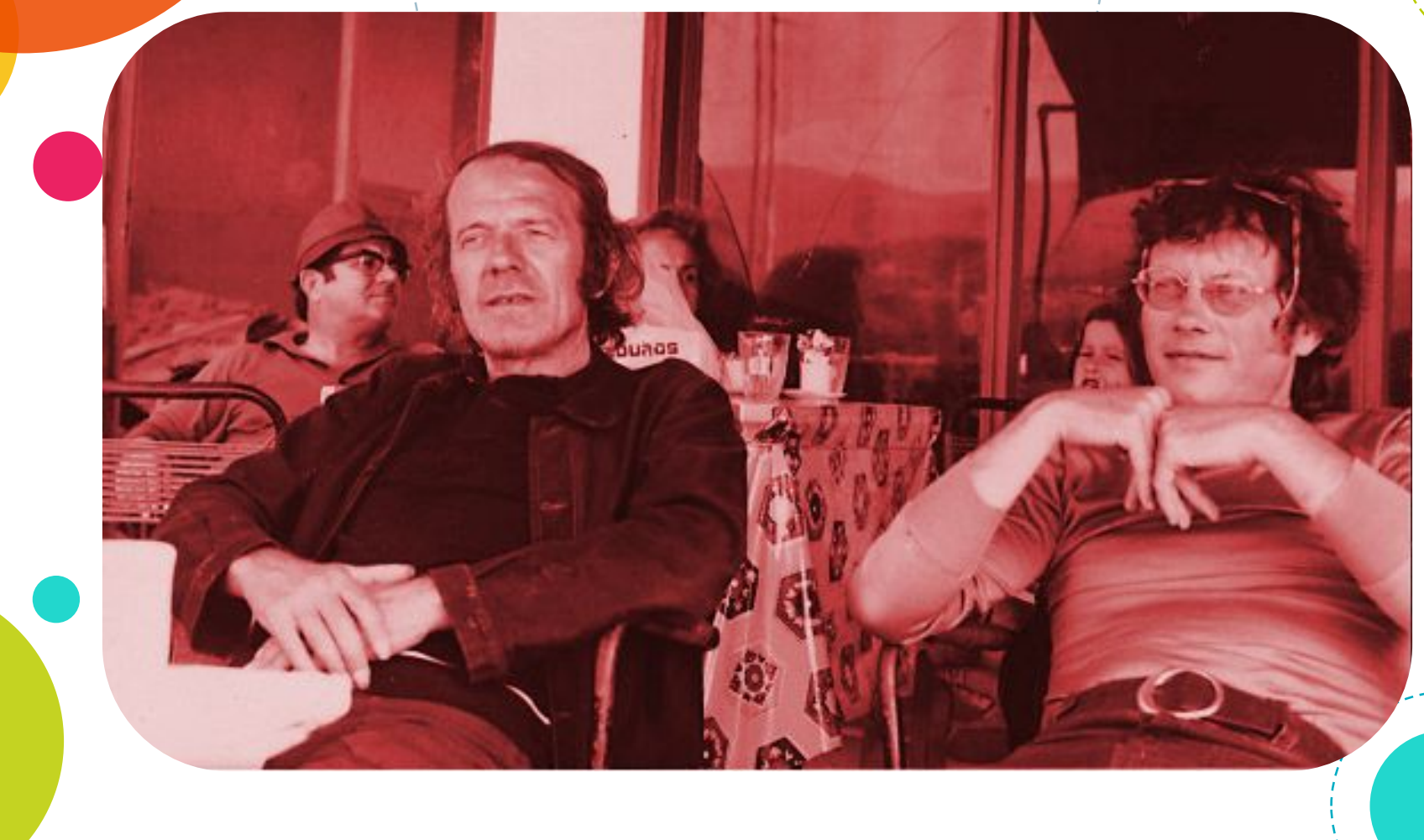




\section{Assemblage}

- An ensemble of parts (material or non-material) that come together to produce a whole.

- The assemblage is a "chaotic network of habitual and non-habitual connections, always in flux, always reassembling in different ways" (Potts, 2004: 19).

- Body is an assemblage: different parts that come together to produce a whole, always re-assembling, and is made of material and non-material bodies.

- Desire is produced through these relations.

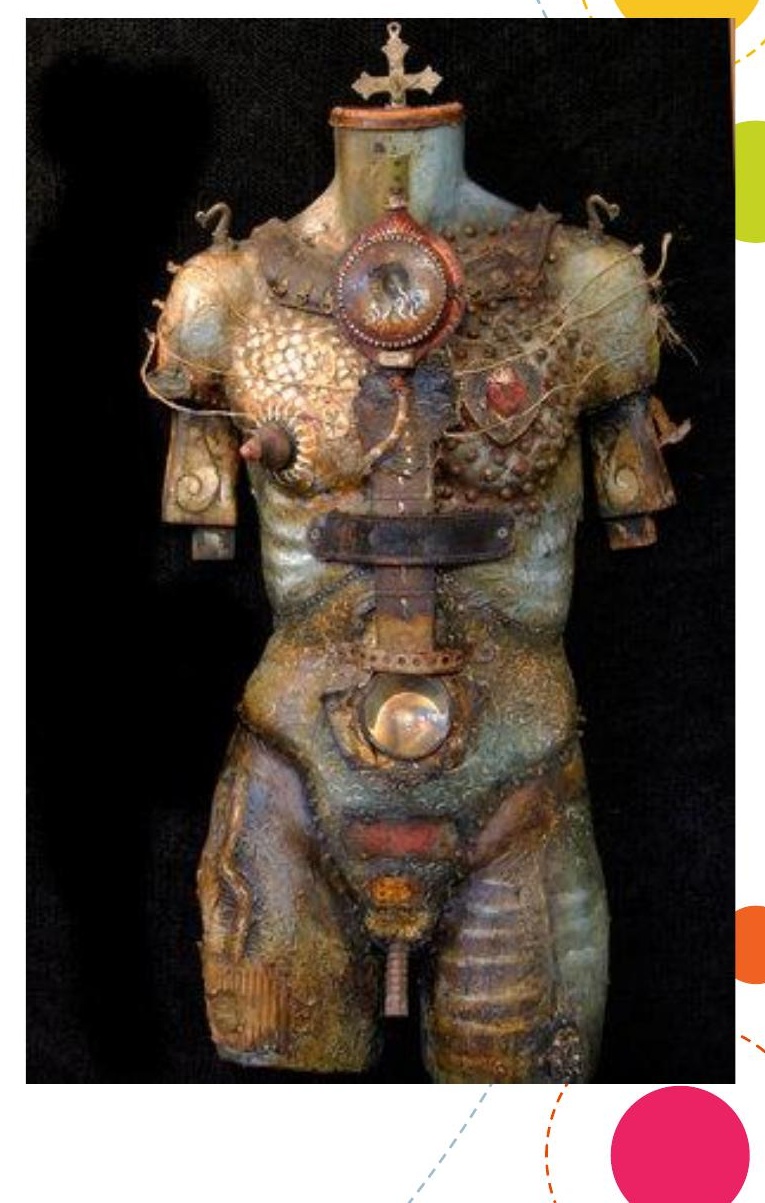




\section{Affect}

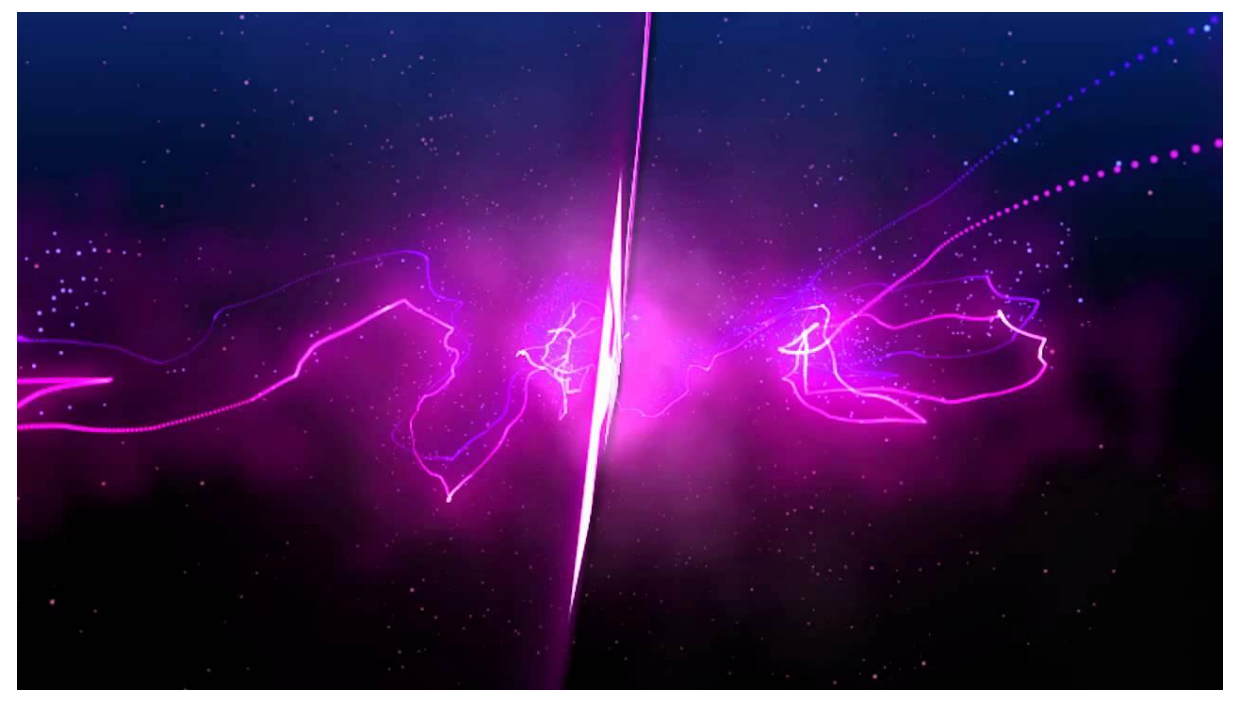

Do not ask: What is a thing? Ask: What can it do? 


\section{Methods as Assemblage}

Critical Ethnography (Thomas, 1993)

- Setting: QueerTEENS (Auckland, NZ)

$\circ \quad$ Participants: 11 Queer Men.

- Data Generation:

- 5 Group Interviews (avg. 38 minutes)

- 6 Individual Interviews (avg. 40 minutes)

○ Data Analysis:

- Dredging (Fox \& Alldred, 2017)

- Mapping (Ringrose \& Coleman, 2013)

- Crystallization (Ellingson, 2009).

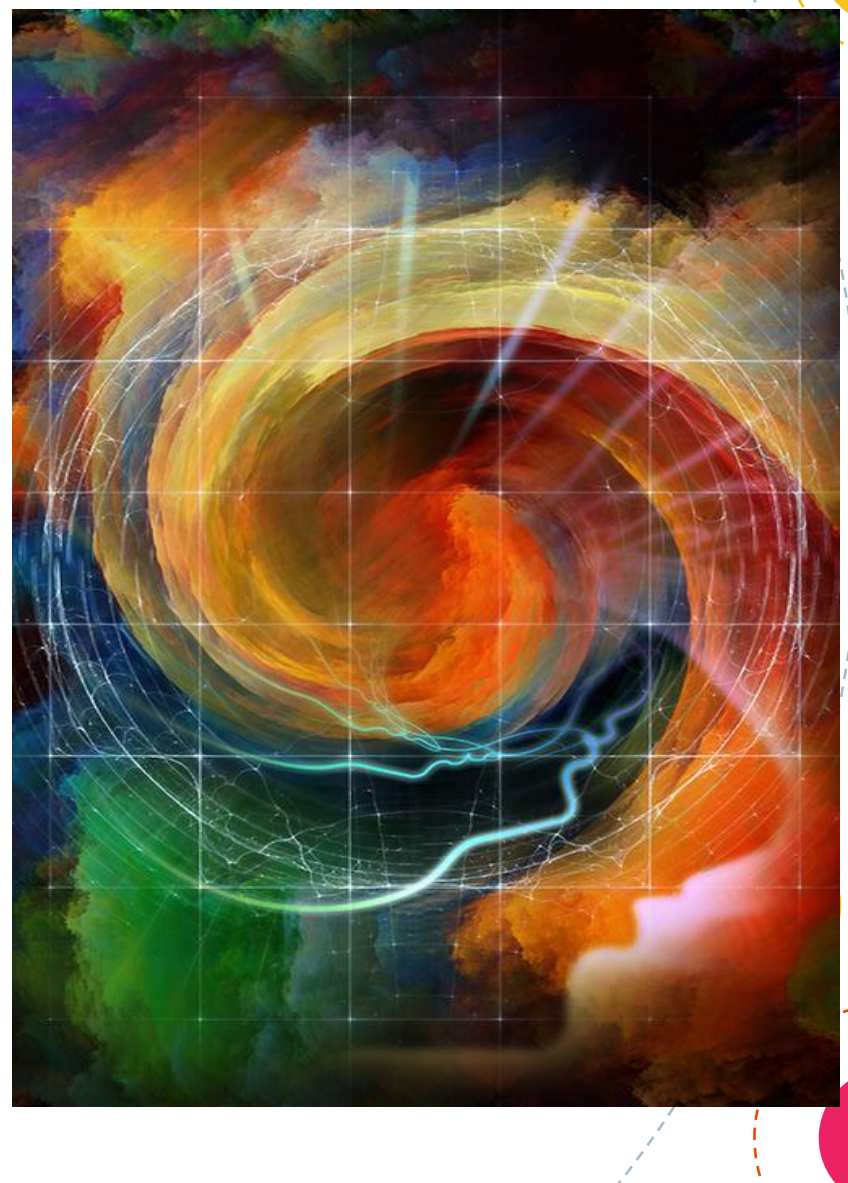


Key Findings 


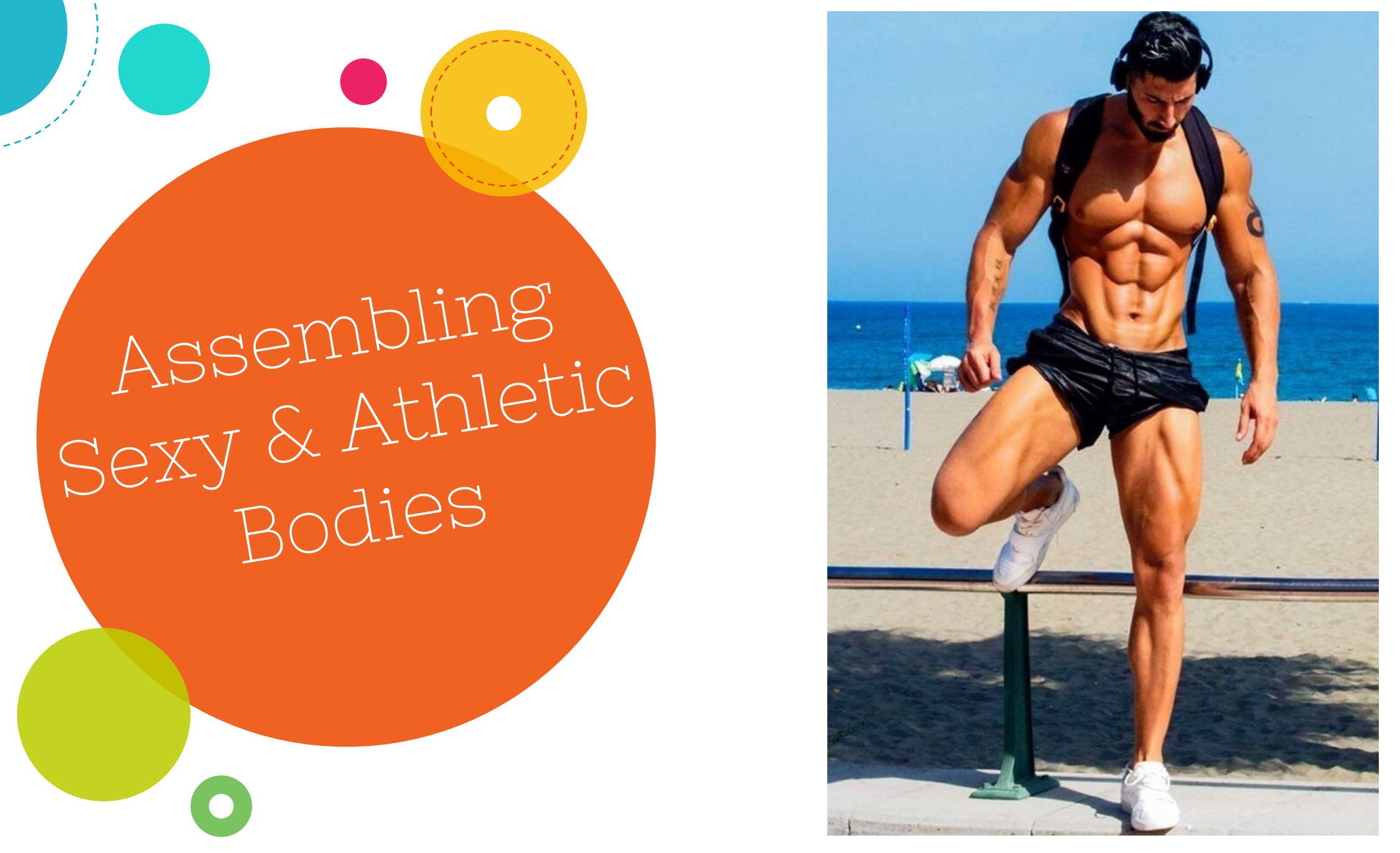


Ethnicities-Femininities-BreastsCapitalism-HeterosexualityMasculinities-Muscles 


\section{Men's Bodies - Viewing- Rules-Hot Men - Pants-Body Parts- Excitement}




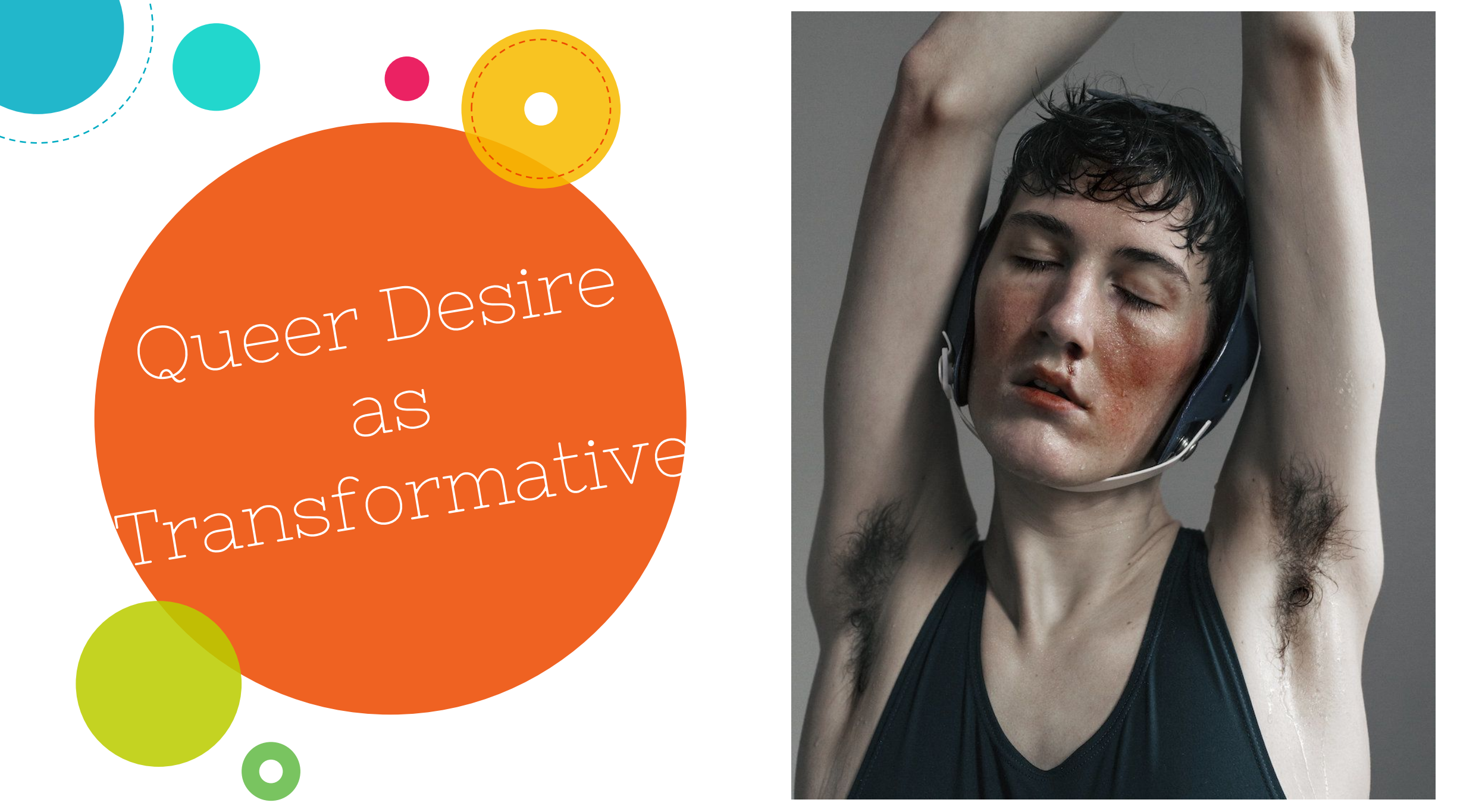




\section{Masculinities- Femininities-Makeup- Capitalism- Confidence-Pleasure- Challenge}




\section{Discussion}

- Natural/ Social Binary

- Desire as produced in PE

- Queer Potential to Transform PE 